\title{
Olive Mill Wastewater Treatment: A Recent Review
}

\author{
Linda Al-Hmoud"), Basel Al-Saida ${ }^{2)}$, Arwa Sandouqa ${ }^{1)}$ \\ ${ }^{1)}$ Chemical Engineering Department, School of Engineering, The University of Jordan, Amman 11942, Jordan \\ 2) Department of Chemistry, Faculty of Science, Al-Balqa Applied University, Salt 19117, Jordan
}

Olive oil-producing countries in the Mediterranean region generate a considerable amount of olive mill wastewater $(\mathrm{OMW})$, contributing to a severe environmental polluting issue due to its high pollution load. This effluent is exceptionally toxic to the whole soil-air-water ecosystem, and the living organisms inhabiting it (i.e., plants, animals, aquatic organisms, microorganisms, etc.). Many researchers have assessed the efficiencies of different treatment techniques to find an environmentally friendly and economically viable solution to be generally adopted. In light of that, the present review article summarizes the state-of-the-art concerning the OMW treatment options, with their pros and cons when possible.

Keywords: olive mill wastewater (OMW); physical treatment, chemical treatment, integrated treatment

\section{Introduction}

In the Mediterranean countries, olive oil production is an important economic activity among agro-industrial production. Simultaneously, the discharge of Olive Mill Wastewater (OMW) is a severe problem in these regions. In Jordan, olive oil production is one of the major agricultural industries, with 21 thousand tons produced yearly. In 2018, the process of olive oil extraction generated more than 120,000 m3 of olive mill wastewater (OMW), also known as Zebar, along with 33 thousand tons of olive cake (Department of Statistics, 2018, Ministry of Agriculture 2019). OMW's composition depends on several factors, such as the climate, cultivation, and grinding method used to produce olive oil. Several processes are used to produce olive oil, such as traditional pressing and two-phase and three-phase decanting processes. A brief presentation of the two major continuous oil extraction systems is shown in Figure 1 (Tsagaraki et al., 2007).

In general, OMW is characterized by its strong odor, acidity, dark color, and high organic load (COD, BOD), total dissolved solids (TDS), and high concentration of phenols (Al Bawab et al., 2018a, Azzam 2018, Domingues et al., 2018). In terms of pollution effect, $1 \mathrm{~m} 3$ of OMW is equivalent to $100-200 \mathrm{~m} 3$ of domestic sewage. Its uncontrolled water reservoir disposal leads to severe problems for the natural water bodies (groundwater reservoirs, aquatic surface reservoirs, seashores, and sea) and ecosystems. (Tsagaraki et al., 2007). Table 1 shows that in Jordan, OMW contains high phenolic contents, high COD, high total suspended solids (TSS), high total dissolved solids (TDS), high concentrations of cations and anions, and low $\mathrm{pH}$ value. The high organic load (chemical and biochemical oxygen demand may reach up to 100 to $200 \mathrm{~g} / \mathrm{L}$ ) of OMW makes it hard to manage and difficult to meet the legal thresholds for their discharge to the environment. The presence of toxic compounds in their constitution makes the common biological treatments inefficient.

Consequently, several methods have been proposed and developed to reduce the environmental impact of OMW. These methods can be classified into physical, chemical, and biological processes. There are also

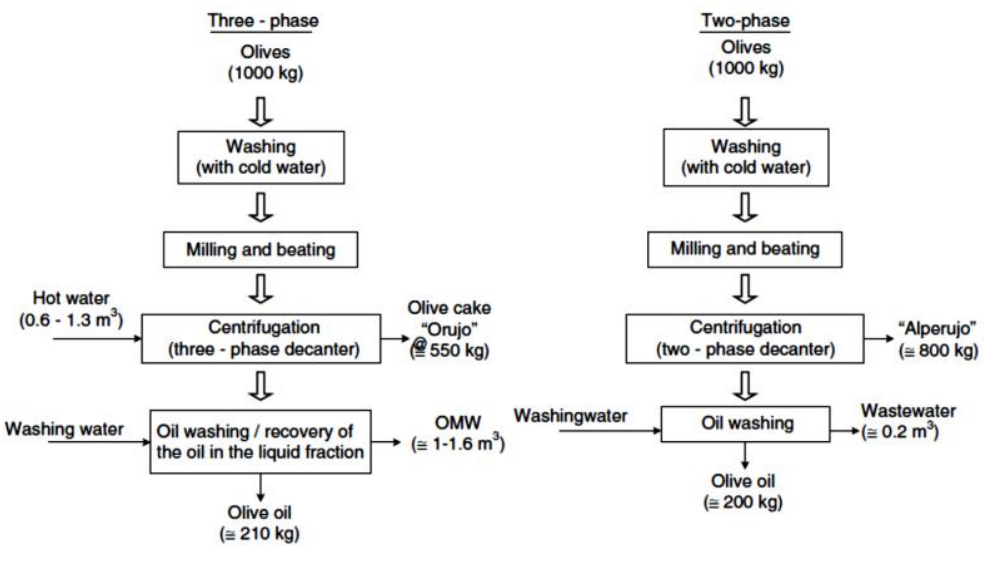

Fig. 1 Three- and two-phase centrifugation systems for olive oil extraction (Tsagaraki et al., 2007) integrated methods, where more than one treatment method is used in series to achieve the required elimination goal. This review aims to present different ways proposed and investigated recently to eliminate and reduce OMW pollutants to make them suitable to be discharged to the environment.

Received on November 17, 2020; accepted on November 28, 2020, correspondence concerning this article should be addressed to L. Al-Hmoud (E-email address: $\underline{\text { 1.alhmoud@ ju.edu.jo ). ORCiD ID for Linda al-Hmoud https://orcid.org/0000-0002-5560-1060 }}$ 


\section{OMW Treatment Methods}

Various methods have been tested to find an efficient and cost-effective treatment process/system for olive mill wastewater (OMW). These methods are based on chemical, biological, and physical scientific aspects and have often used more than one form. Some methods tried to recover and recycle some valuable components from OMW. Accordingly, the numerous treatment processes that have been recently proposed and investigated are presented here under three categories: physical, chemical, and integrated treatments.

Table 1 Characteristics of OMW in Jordan (Azzam et al., 2015, Al Bsoul et al., 2019, Al-Essa. 2018, Al-Shaweesh et al., 2018)

\begin{tabular}{|c|c|c|c|c|c|c|c|c|c|c|c|}
\hline $\begin{array}{c}\text { Property } \\
\text { Unit }\end{array}$ & $\begin{array}{c}\mathrm{pH} \\
- \\
\end{array}$ & $\begin{array}{c}\text { Phenols } \\
\mathrm{mg} / \mathrm{L}\end{array}$ & $\begin{array}{c}\mathrm{COD} \\
\mathrm{g} / \mathrm{L}\end{array}$ & $\begin{array}{l}\text { TSS } \\
\mathrm{g} / \mathrm{L}\end{array}$ & $\begin{array}{c}\text { TDS } \\
\mathrm{g} / \mathrm{L}\end{array}$ & $\begin{array}{c}\mathrm{Ca} \\
\mathrm{mg} / \mathrm{L} \\
\end{array}$ & $\begin{array}{c}\mathrm{Cu} \\
\mathrm{mg} / \mathrm{L}\end{array}$ & $\begin{array}{c}\mathrm{K} \\
\mathrm{g} / \mathrm{L} \\
\end{array}$ & $\begin{array}{r}\mathrm{Mg} \\
\mathrm{mg} / \mathrm{L} \\
\end{array}$ & $\begin{array}{c}\mathrm{Na} \\
\mathrm{mg} / \mathrm{L}\end{array}$ & $\begin{array}{r}\mathrm{Zn} \\
\mu \mathrm{g} / \mathrm{L} \\
\end{array}$ \\
\hline Value & 4.6-5.9 & $300-3000$ & $10-50$ & $5-21$ & $2-35$ & 2.1 & 0.9 & $0.2-8$ & 1.9 & 0.7 & 33 \\
\hline
\end{tabular}

\subsection{Physical treatment}

OMW physical treatment methods presented here include liquid extraction, filtration/non-filtration, flotation, adsorption, flocculation, coagulation, used alone or in combination with one or the other. Table $\mathbf{2}$ summarizes the reviewed physical treatment methods, their targets/aims, and main results and findings. Abu-Lafi et al., (2017) investigated the enrichment of phenolic compounds from OMW by liquid-liquid extraction. Ethyl acetate was found to be an excellent solvent for the extraction and enrichment process. Ethyl acetate was found to be an excellent solvent for the extraction and enrichment process. Results showed that the extract contains mainly hydroxytyrosol and tyrosol among OMW's main three phenolic compounds, but no oleuropein. Further, OMW extract has strong potential to act as a natural antioxidant and preservative for olive oil. Its addition to olive oil samples positively influenced olive oil's stability as reflected by its acid value, peroxide value, and total phenolic content. The extract's antimicrobial activity was also investigated and showed positive activities as antibacterial and antifungal and activities against yeast. Liquid extraction was also used to isolate phenolic compound content from OMW, before passing it through a membrane filtration system (Sygouni et al., 2019). OMW was collected from olive mills using two-phase extraction systems. The liquid extraction with water and ethanol mixture was optimized by testing extraction parameters such as solvents' mixture, duration, and temperature) at laboratory scale. The maximum total phenolic content (TPC) recovery was attained when a mixture of 50\% ethanol and 50\% distilled water (50\% E-50\%W) was used as a solvent. Then extracted solution was fed to a pilot membrane filtration system consisting of ultrafiltration (UF), nanofiltration (NF) and reverse osmosis (RO) membranes in series. UF removed all fats, lipids, and solids while the phenolic and all remaining organic compounds were concentrated in the NF and/or RO retentates. The final effluent in the permeate stream after the RO membrane was found almost clean from polyphenols (10 mg/L), whereas the low concentration of carbohydrates (146 mg/L) and low COD ( $284 \mathrm{mg} / \mathrm{L})$ values were detected. This COD value is much lower than the feed stream $(>32,000 \mathrm{mg} / \mathrm{L})$ value, giving evidence that it is possible to clean the two-phase OMW with simultaneous recovery of high amounts of phenolic substances. Gikas et al., (2018) found that hybrid natural systems can be used efficiently and economically in treating OMW. The set-up consisted of two hybrid pilot-scale natural systems. The first system comprised two open tanks, one vertical flow constructed wetland and the one free water surface flow, while the second one comprised two open tanks, with calcium hydroxide added to one of them, and one free water surface flow. The results showed that both natural systems are effective in pollutants removals such as TSS ( 94\%), COD $(\sim 65 \%)$, and PHE ( $64 \%)$ in the liquid phase. Calcium hydroxide addition had no significant effect on system efficiency. Moreover, the final pollutant effluent concentrations remained high for disposal in water bodies or used for irrigation. Ait-hmane et al., (2018) examined raw OMW treatment by multi-soil-layering (MSL) ecotechnology. The system comprises soil mixture blocks (soil-sandy texture, sawdust, metal iron, and charcoal) arranged in a brick-like pattern and surrounded by permeable gravel layers to avoid clogging. OMW was diluted by urban wastewater and fed to the system at a continuous hydraulic loading rate (HLR) of 100 $\mathrm{L} /\left(\mathrm{m}^{2}\right.$.day). Results showed that increasing OMW concentration in the feed to MSL from $10 \%$ to $50 \%$ induced a $\mathrm{pH}$ alkalizing (from 7.9 to 8.5 ) of treated water and enhanced the system efficiency. Increasing OMW concentration improved TSS (from 95.7\% to $99.1 \%$ ), COD (from $85.0 \%$ to $91.8 \%$ ), BOD (from $54.4 \%$ to $82.6 \%$ ), total phosphorus (from $55.5 \%$ to $90.1 \%$ ), $\mathrm{NH}_{4}{ }^{+}$(from $69.2 \%$ to $98.6 \%$ ) and phenolic compounds (from $91.5 \%$ to $100 \%$ ) reduction. However, when the percentage of OMW percentage in the system feed exceeded $50 \%$, the system efficiency decreased for all parameters. A clogging starting sign (acidic pH, deficient residual oxygen in the outlet) appeared. At 50\% OMW concentration, the maximum superficial organic load of $1.4 \mathrm{~kg} \mathrm{COD} /\left(\mathrm{m}^{2} . \mathrm{day}\right)$ and $0.516 \mathrm{~kg}$ $\mathrm{BOD}_{5} /\left(\mathrm{m}^{2}\right.$.day) were obtained, assuring MSL to be an efficient, low-cost treatment method. 
Table 2 Summary of Reviewed Physical Treatment Methods, Target, and main Results and Findings.

\begin{tabular}{|c|c|}
\hline $\begin{array}{l}\text { Process } \\
\text { Target/Aim }\end{array}$ & Process \\
\hline $\begin{array}{l}\text { Removal of } \\
\text { pollutants }\end{array}$ & $\begin{array}{l}\text { Hybrid pilot-scale natural systems } \\
\text { Multi-soil-layering (MSL) } \\
\text { ecotechnology } \\
\text { Non-oxidized and oxidized Granular } \\
\text { Activated Carbons (GAC, GAC-OX) } \\
\text { particles impregnated with surface- } \\
\text { active materials (nonionic surfactants } \\
\text { (Span 20, Span 80, and Brij 93) }\end{array}$ \\
\hline $\begin{array}{l}\text { Isolation of } \\
\text { phenolic } \\
\text { compounds }\end{array}$ & $\begin{array}{l}\text { Liquid-liquid extraction with ethyl } \\
\text { acetate } \\
\text { Liquid extraction followed by } \\
\text { membrane filtration } \\
\text { Surfactant enhanced aquifer } \\
\text { remediation (SEAR). } \\
\text { Modified surfactants were used: sodium } \\
\text { polypropylene oxides sulfate (L167- } \\
\text { 4S), combined with cationic } \\
\text { hydrotropes TBAB }\end{array}$ \\
\hline $\begin{array}{l}\text { Removal of } \\
\text { TSS and oil } \\
\text { and grease } \\
\text { Removal of } \\
\text { TSS, TOC, } \\
\text { and oil and } \\
\text { grease }\end{array}$ & $\begin{array}{l}\text { Filtration by tubular honeycomb silicon } \\
\text { carbide membranes }\end{array}$ \\
\hline $\begin{array}{l}\text { Removal of } \\
\text { TSS, FM, } \\
\text { TPh, and } \\
\text { COD }\end{array}$ & $\begin{array}{l}\text { Combined process (filtration, } \\
\text { coagulation, flocculation) }\end{array}$ \\
\hline
\end{tabular}

Removal of TSS, TPh, and COD
Combined coagulation-flocculation process

Adsorption by activated carbon prepared from waste "peach stones" carbonized at $900{ }^{\circ} \mathrm{C}$

Adsorption by resins (Amberlite ${ }^{\mathrm{TM}}$ XAD 4, XAD 16, and FPX 66 resins)

Adsorption by resins (Amberlite ${ }^{\mathrm{TM}}$ FPX 66 resins)

phenolic compounds
Both natural systems are effective in pollutants removal, such as TSS ( 94\%), COD ( 65\%), and polyphenols ( 64\%).

Efficient, low-cost treatment method

Economical process for OMW remediation

Ethyl acetate is found to be an excellent solvent for phenolic compound extraction and enrichment from OMW.

OMW extract has strong potential to act as a natural antioxidant and preservative for olive oil

Efficient lowering of phenols concentration to $(10 \mathrm{mg} / \mathrm{L})$, carbohydrates to $(146 \mathrm{mg} / \mathrm{L})$, and COD to ( 284 mg/L).

The recovery of phenols using a mixture of $4 \%$ L167-4S and TBAB (1:2 molar ratio) was 99.5-99.8\%, while by using a combination of $4 \%$ L167-4S: TBAB (1:2 molar ratios) the recovery was $95 \%$

Efficient to remove TSS and oil and grease.

Fraga et al., 2017

High rejections were obtained for total suspended solids ( 83 to $>99$ $\%$ ), total organic carbon (64 to $99 \%$ ), chemical oxygen demand (53 to $77 \%$ ), and oil and grease (67 to $>82 \%$ ).

Filters lead to high TSS $(\sim 82.5 \%)$ and fatty matter $(\sim 73.8 \%)$ removal, with only $11.3 \%$ total phenolic compounds (TPh) and $23.2 \%$ COD depletion.

Coagulation/flocculation operating at $\mathrm{pH}=5$ with $250 \mathrm{mg} / \mathrm{L}$ ferric chloride coagulant and $5 \mathrm{mg} / \mathrm{L}$ of polyelectrolyte flocculant can remove $\sim 10.8 \%$ of $\mathrm{TPh}$ and $31.3 \%$ of COD.

Combination of the lime and the ferric chloride allows the removal of $87 \%$ of TSS, $58 \%$ of COD, and $75 \%$ of phenolic compounds

Reduction of phenols by $91 \%$ at the optimal conditions (acidic media: $\mathrm{pH}=2, \mathrm{~T}=20^{\circ} \mathrm{C}, 2 \mathrm{~g}$ of activated carbon $/ 100 \mathrm{ml}$ of OMW, and 1 hour of contact time).

Reduction of $75 \%$ of soluble phenolic content was observed when $20 \%$ of FPX 66 was applied compared to $65 \%$ reduction of phenolics with $20 \%$ of XAD 4 and XAD 16.

A reduction of $68 \%$ polyphenols and $60 \%$ carbohydrates content.

Both Langmuir and Freundlich models fitted the equilibrium data, and kinetic data followed a pseudo-second-order model.

The quantity of adsorbed polyphenols was $161 \mathrm{mg} / \mathrm{g}$ at $25^{\circ} \mathrm{C}$.

Both Langmuir and Freundlich model models are favorable to describe the adsorption phenomena, and kinetic data were realized at the pseudo-second-order model.

Allaoui et al., 2020

Abu-Lafi et al., 2017

Sygouni et al., 2019

Al Bawab et al. 2017

Sanches et al., 2017

Enaime et al., 2019

Alaoui et al., 2016

Ziati et al., 2017

Vavouraki et al., 2020

Vavouraki. 2020

Adsorption of polyphenols was exothermic in nature; $\Delta \mathrm{H}^{0}<0$, ordered; $\Delta \mathrm{S}^{0}<0$, and spontaneous; $\Delta \mathrm{G}^{0}<0$. 
Adsorption by natural Clay, volcanic tuff (VT), and charcoal

Removal of phenolic compounds and heavy metal

\section{Adsorption by Jordanian bentonite} activated by hydrochloric acid at $25^{\circ} \mathrm{C}$

Adsorption by titanium dioxide $\left(\mathrm{TiO}_{2}\right)$ nanoparticles

Removal of

organic

content

Adsorption by hybrid materials by batch and continuous column methods

Montmorillonite (Mt) mineral clay functionalized with the biosurfactant Quillaja saponins (SPN)

Removal of Treatment by activated sludge (AS)

polyphehenols and organic content

Removal of TSS, TPh, and COD

A continuous pilot system of activated sludge (AS)

\section{Combined coagulation-flocculation} process

Combined coagulation-flocculation by an integrated system comprising of 0.1

Removal of polyphenols, $\mathrm{g}$ of $\gamma-\mathrm{Fe}_{2} \mathrm{O}_{3}$ nanoparticles (particle size less than $10 \mathrm{~nm}$ ) and $1 \mathrm{~kg}$ sand

COD, and

BOD

Coagulation and flocculation by aluminum sulfate (Alum), and chitosan
Reductions in both COD (40\%) and phenols (80\%) were observed when activated charcoal was employed, without any reasonable reductions when treated natural Clay and treated natural volcanic tuff (VT) were used alone.

Azzam. 2018

When all three materials were employed in combinations, results were strongly dependent on the used charcoal level.

Optimum adsorbent concentration is found to be $1 \mathrm{~g}$ of activated bentonite $/ 10 \mathrm{~mL}$ of OMW. The percentage uptakes exceeded $99 \%$ for $\mathrm{Zn}, \mathrm{Fe}$, and $\mathrm{Mn}$ ions. It reached $65.2 \%$ for $\mathrm{K}^{+}$and $61.5 \%$ for $\mathrm{Na}^{+}$ ions. Phenolic compounds removal reached $66 \%$ at the optimum adsorbent concentration.

The three examined $\mathrm{TiO}_{2}$ nanoparticle concentrations (1.0, 1.5, 2.0 $\mathrm{g} / \mathrm{L}), 1.5 \mathrm{~g} / \mathrm{L}$ of $\mathrm{TiO}_{2}$ caused the maximum COD uptake, in which it dropped from $1000 \mathrm{ppm}$ to about $100 \mathrm{ppm}$ in $120 \mathrm{~min}$.

Adsorption equilibrium data can be fitted to Freundlich isotherm, and the adsorption kinetics follow a pseudo-second-order reaction.

The adsorption process was spontaneous and exothermic.

Both batch and column methods were influential in OMW's decontamination, where $60-78 \%$ organic content reduction was attained.

COD and polyphenols were highly eliminated (90\%, 92\%, respectively)

The continuous pilot system effectively removed $95 \%$ of COD and 93\% of the phenolic compounds.

Al-Essa. 2018

Al Bsoul et al., 2019

Combination of the lime and the ferric chloride allows the removal of $87 \%$ of TSS, $58 \%$ of COD, and $75 \%$ of phenolic compounds

Removed $99 \%$ of total phenols, $97.2 \%$ of COD, and $95.3 \%$ of $\mathrm{BOD}_{5}$

found that alum performance is better than chitosan, at $\mathrm{pH}$ values $\geq$ 4.0. The use of $800 \mathrm{mg} / \mathrm{L}$ of alum led to reductions of about $17 \%$, $57 \%$, and $63 \%$ in TOC, COD, and phenols, respectively.
Al-Shaweesh et al., 2018

Sciascia et al., 2019

Elmansour et al., 2020

El Moussaoui et al., 2018

Alaoui et al., 2016

Vuppala et al., 2019

The isolation of phenolic compounds from wastes faces many challenges. Because they do not need expensive equipment and organic solvents, and their energy consumption is relatively low, surfactants have been used for phenolic compounds separation from wastes. Surfactant enhanced aquifer remediation (SEAR) technology was evaluated (Al Bawab et al., 2017) for separating phenolic compounds from OMW. They proposed a new modified surfactant, sodium polypropylene oxides sulfate (L167-4S), combined with cationic hydrotropes tetra butyl ammonium bromide (TBAB) in 1:1 and 1:2 molar ratios. Phenol was used as a model sample of the phenolic compounds in the OMW to evaluate phenolic compounds' recovery efficiency from OMW. The amount of the needed surfactant to extract the phenol was determined using the three-dimensional phase behavior of the phenol, water, and the proposed surfactants. Their study results show that the recovery of phenols using a mixture of 4\% L167-4S and TBAB (1:2 molar ratio) was 99.5-99.8\% and that COD recovery was $99.5-99.8 \%$. When the mixture of 4\% L167-4S: TBAB (1:2 molar ratios) was introduced into the real OMW sample, $95 \%$ of organic content was removed from the aqueous phase. On a different aspect, surfactants were used to enhance OMW's remediation by cost-effective media of two granular activated carbon (Al Bawab et al., 2018b). Non-oxidized Granular Activated Carbons (GAC) and oxidized Granular Activated Carbons (GAC-OX), particles impregnated with surface-active materials (nonionic surfactants (Span 20, Span 80, and Brij 93) at three different concentrations (10, 30, $55 \mathrm{mM}$ ) were investigated for OMW treatment. Experimental results showed that $10 \mathrm{mM}$ nonionic surfactant concentration was the optimum concentration used in media preparation. Increasing the surfactant concentration to 30 and $55 \mathrm{mM}$ causes a considerable reduction in the phenolic compounds removal percentage. Also, using the oxidized version of $10 \mathrm{mM}$ impregnated GAC media enhanced the percent phenol removal. For both GAC-OX and GAC adsorbent media, the percent removal increases within 15 days during soaking with media without mixing. After 15 days, the percent removal was relatively reduced, which may be due to phenolic compounds desorption. The used adsorbent media is claimed to provide an economical way for OMW remediation. 
Activated carbon on its own was also used for the adsorption of phenolic compounds from OMW. Activated carbon prepared from waste "peach stones" was studied by Ziati et al., (2017). The peach stones were cleaned, dried, crushed, and finally carbonized at $900^{\circ} \mathrm{C}$. They showed that using this adsorbent for polyphenols concentration reduction resulted in $91 \%$ removal at the optimal conditions (acidic media: $\mathrm{pH}=2$, ambient temperature: $\mathrm{T}=20^{\circ} \mathrm{C}, 2 \mathrm{~g}$ of activated carbon $/ 100 \mathrm{ml}$ of $\mathrm{OMW}$, and 1 hour of contact time). Furthermore, the adsorption kinetics was rapid, adequately described by the Freundlich model, and pseudo-second-order type.

The adsorption process is believed to be an efficient technique in removing contaminants from OMW. Recently, along with activated carbon, polymeric resins, titanium dioxide, and other adsorbent extracted from a natural source was investigated in adsorbing phenolic compounds from OMW. Amberlite ${ }^{\mathrm{TM}}$ XAD 4, XAD 16, and FPX 66 resins were examined in different mass ratios (10, 15 , $20 \%$ ) for phenolic removal from diluted 50\% OMW (Vavouraki et al., 2020). A reduction of 75\% of the soluble phenolic content was observed when $20 \%$ of FPX 66 was applied compared to $65 \%$ reduction of phenolics with $20 \%$ of XAD 4 and XAD 16 . During batch anaerobic digestion experiments of resin pre-treated $\mathrm{OMW}$ at mesophilic conditions $\left(37^{\circ} \mathrm{C}\right)$, methane production was elevated for FPX-pretreated OMW. Polyphenols in OMW were proved to inhibit OMW fermentation and, thus, methane production. More detailed adsorption experiments were conducted to examine FPX 66, a cross-linked styrene-divinylbenzene polymer, as a sorbent (Vavouraki, 2020). It was used to remove polyphenols and carbohydrates derivatives from OMW. The results showed a 68 and $60 \%$ reduction of polyphenols and carbohydrates contents, respectively, within the first one hour, at a pH of 5.24. Moreover, polyphenol removal increased by increasing polyphenol concentration but decreased from $77 \%$ to $40 \%$ by increasing OMW pH value from 7.5 to 9. Both Langmuir and Freundlich models fitted the equilibrium data, and kinetic data showed that adsorption of polyphenols derived from OMW on FPX 66 resin followed the pseudo-second-order model. A $70 \%$ polyphenols recovery and $60 \%$ carbohydrates recovery were achieved upon adsorbent resin regeneration with ethanol/isopropanol mixture (in a 50 to $50 \%$ ) ratio at $\mathrm{pH}=4$.

Natural Clay (ghassoul) was used as an adsorbent in the removal of polyphenols from OMW after being analyzed using XRD, SEM/EDX, FTIR, surface area (BET method), thermal analysis (TGA/ DTA), and X-ray fluorescence (XRF) (Allaoui et al., 2020). The results showed that the adsorbed polyphenols' quantity was $161 \mathrm{mg} / \mathrm{g}$ at $25^{\circ} \mathrm{C}$, and decreased with increasing temperature. Both Langmuir and Freundlich model models are favorable to describe the adsorption phenomena of polyphenols onto ghassoul clay. However, the Freundlich model is more suitable, and kinetic data was realized at the pseudo-second-order model. Furthermore, the thermodynamic data indicates that the adsorption of polyphenols was exothermic in nature; $\Delta \mathrm{H}^{0}<0$, ordered; $\Delta \mathrm{S}^{0}<0$, and spontaneous; $\Delta \mathrm{G}^{0}<0$.

Other simple natural local materials, natural Clay, volcanic tuff (VT), and charcoal, were also investigated as possible adsorbents employed to decrease the high levels of phenols and organic matter of OMW (Azzam 2018). When used alone, treated natural Clay and treated natural volcanic tuff (VT) did not generally produce reasonable reductions in COD levels nor phenols concentrations present in OMW. However, when activated charcoal was employed, significant reductions in OMW's COD and phenols concentrations were observed, $40 \%$ and $80 \%$, respectively. When all three materials were employed in combinations, the results showed a strong dependency on the levels of charcoal used.

Fast, simple, green, non-toxic, and the economical method was used for OMW treatment (Al-Essa. 2018). Activated Jordanian bentonite activated by hydrochloric acid at $25{ }^{\circ} \mathrm{C}$ was used as an adsorbent and applied in batch and column techniques. After studying several parameters that affected the adsorption capacity, it was found that maximum removal of total phenolic compounds and heavy metal ions ( $\mathrm{Zn}, \mathrm{Fe}$, and $\mathrm{Mn}$ ) was achieved at $\mathrm{pH} 6$ and that the adsorption capacity of phenolic compounds was enhanced with an increase in the solution temperature and with the adsorbent dose. The optimum adsorbent concentration is found to be $1 \mathrm{~g}$ of activated bentonite $/ 10 \mathrm{ml}$ of OMW. The percentage uptakes exceeded $99 \%$ for $\mathrm{Zn}, \mathrm{Fe}$, and Mn ions, while it reached 65.2 and 61.5 for $\mathrm{K}^{+}$and $\mathrm{Na}^{+}$ions, respectively. The efficiency of phenolic compounds removal increases with an increase in solution temperature and adsorbent dose, with $66 \%$ removal achieved at the optimum adsorbent concentration.

Similar findings were observed when titanium dioxide $\left(\mathrm{TiO}_{2}\right)$ was investigated as an adsorbent in OMW treatment (Al Bsoul et al., 2019). COD removal efficiency, adsorbent amount, temperature, and $\mathrm{pH}$ value were studied. Isotherm studies revealed that the adsorption equilibrium data could be fitted to Freundlich isotherm, and the kinetic study indicated that adsorption did follow a pseudo-second-order reaction. The results also showed that the adsorption process was spontaneous and exothermic. Also, among the three examined $\mathrm{TiO}_{2}$ nanoparticle concentrations $(1.0,1.5,2.0 \mathrm{~g} / \mathrm{L}), 1.5 \mathrm{~g} / \mathrm{L}$ of $\mathrm{TiO}_{2}$ caused the maximum COD uptake, in which it dropped from $1000 \mathrm{ppm}$ to about $100 \mathrm{ppm}$ in $120 \mathrm{~min}$. COD uptake was inversely proportional to temperature and salts' addition (e.g., sodium chloride, $\mathrm{NaCl}$ and potassium chloride, $\mathrm{KCl}$ ). Finally, $\mathrm{COD}$ uptake was found to increase as the $\mathrm{pH}$ increases to a particular value (4.9), then fall again; thus, an optimum $\mathrm{pH}$ value was found. Sciascia et al., (2019) used hybrid materials based on montmorillonite (Mt) mineral clay functionalized with the biosurfactant Quillaja saponins (SPN), to accomplish the simultaneous decontamination and valorization of OMW. SPN/Mt hybrids were synthesized by varying $\mathrm{pH}$ and surfactant/clay ratio and characterized by constructing the adsorption isotherms. The performances of these materials were evaluated in the removal of organic content. SPN/Mt hybrids treated real OMW samples using two different protocols; batch and column. In the batch strategy, OMW batch samples were treated by adding dry SPN/Mt hybrids under continuous stirring. Alternatively, the organoclays were packed in a chromatography column filled with multiple alternate layers of sand and organoclay. Both batch and column methods were useful in the decontamination of OMW, where $60-78 \%$ organic content reduction was attained. Regardless of the employed protocol, the clay 
surface's organophilic modification enhances adsorption capability toward the potentially toxic organic molecules present in the OMW. Comparing the two methods, batch treatments can treat a sizeable OMW volume, but further treatments are needed to separate the adsorbed organic compounds for industrial purposes.

The preparation of the columns is both time and products consuming, and the treated OMW volumes are smaller than in batch treatments, but the column treatments present the advantage of already having a packed organoclay from which the chromatographic separation of the different organic compound could be more comfortable. Elmansour et al., (2020) investigated the possibility of treating OMW by activated sludge (AS) pilot, which was highly diluted (1\%) by urban wastewater (UWW). Successful biomass growth of $7.12 \mathrm{~g}_{\mathrm{MLVSS}} / \mathrm{L}$ and activity were obtained despite the high polyphenols' concentration (up to $128 \mathrm{mg} / \mathrm{L}$ ). High eliminations of COD (90\%) and polyphenols (92\%) were attained. Similar aspects have been conducted by El Moussaoui et al., (2018) but in a continuous mode. Their results also showed successful growth of the biomass, and the continuous pilot system was capable of effectively removing $95 \%$ of COD and $93 \%$ of the phenolic compounds. Fraga et al., (2017) filtered OMW using new tubular honeycomb silicon carbide membranes (Figure 2) and attained high removals of total suspended solids and oil and grease. They used these new membranes at a pilot scale to treat OMW collected after the sedimentation process at a real wastewater treatment plant. They evaluated the filtration conditions and found that back pulses combined with backwashes help maintain the permeate flux and avoid high transmembrane pressure increase. Results also show that, under total recirculation of the retentate that causes an increased concentration of pollutants in the feed stream, the permeate quality is maintained over time. They suggested using silicon carbide membrane filtration as an alternative to dissolved air flotation and efficiently removing total suspended solids and oil and grease from OMW.

In a study performed by Sanches et al., (2017), real OMW pre-treated by dissolved air flotation was used to assess nanofiltration treatment's feasibility. Four pilot nanofiltration assays were conducted at different volume reduction factors (VRF), the volume ratio between the initial feed of and the retentate: $29,45,58$, and 81 . Data attained demonstrated that nanofiltration can be operated at considerably high VRF values and still effectively remove several components from real OMW pre-treated by dissolved air flotation. A significant flux decline $(\sim 50 \%)$ was observed at the highest VRF, and the increase in osmotic pressure is believed to be the main reason. Considerably high TSS ( 83 to $>99 \%$ ), TOC (64 to $99 \%$ ), COD (53 to $77 \%$ ), and oil and grease (67 to >82\%) removals were obtained across all experiments. The permeate total phenol concentration could not comply with European legislation for discharge into water bodies. The concentration of total phenols determined in the permeate and volatile compounds contributed to COD being above the legal limits. The recovery of phenolic compounds was found to be economically not feasible. Accordingly, the use of advanced oxidation processes (AOPs) to further reduce COD was suggested to comply with legislation regarding these components. A combined process comprising two consecutive olive stone (OS) filters followed by a coagulation-flocculation process was developed to perform an efficient pre-treatment of raw OMW (Enaime et al., 2019). The study results showed that using OS filters leads to high total TSS $(\sim 2.5 \%)$ and fatty matter (FM, 73.8\%) removal from raw OMW, where total phenolic compounds (TPCs) and COD depletion reached 11.3 and $23.2 \%$, respectively. Different parameters affecting the coagulation-flocculation process were studied: $\mathrm{pH}$, coagulant type and concentration, and flocculant type and concentration. The results showed that operating the process at $\mathrm{pH}=5$ with ferric chloride coagulant at a concentration of $250 \mathrm{mg} / \mathrm{L}$ and $5 \mathrm{mg} / \mathrm{L}$ of polyelectrolyte flocculant can remove about $10.8 \%$ of the TP and $31.3 \%$ of the COD.

The combined coagulation-flocculation system attracted many researchers because of its encouraging results toward the treatment of OMW. Alaoui et al., (2016) evaluated the coagulation treatment process's effectiveness with lime and ferric chloride in removing OMW pollutants. Raw OMW was collected from a three-phase olive mill. Their study showed that combining the lime and the ferric chloride allows removing $87 \%$ of TSS, $58 \%$ of COD, and $75 \%$ of phenolic compounds. OMW treatment by this combined coagulation-flocculation system allowed a destabilization of colloidal particles and transformed the phenolic compounds, which facilitated the agglomeration of the hydroxide floc by simple decantation. They suggested adding a chlorination step to reuse treated OMW as wash water or for irrigation of green spaces. After chlorination, the percentages of COD removal and decolorization reach $65 \%$ and $71 \%$, respectively.

Al-Shaweesh et al., (2018) used ferric oxide nanoparticles to reduced total phenols concentration in olive mill wastewater (OMW). When $\gamma-\mathrm{Fe}_{2} \mathrm{O}_{3}$ nanoparticles (particle size less than $10 \mathrm{~nm}$ ) were used as a coagulant, its coagulation-flocculation separation efficiency into two phases was noticed to be weak. However, the removal percentage of total phenols reached $87 \%$. They prepared an integrated system comprising of $0.1 \mathrm{~g}$ of $\gamma-\mathrm{Fe}_{2} \mathrm{O}_{3}$ nanoparticles (particle size less than $10 \mathrm{~nm}$ ) and $1 \mathrm{~kg}$ sand. When this

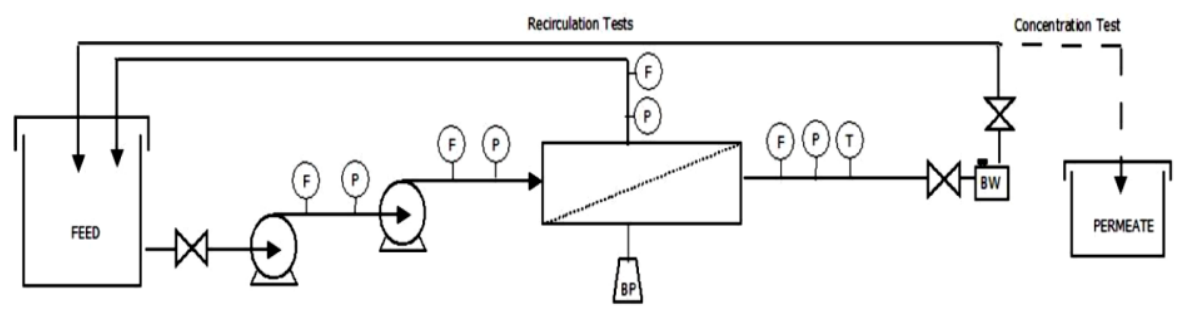

Fig. 2 Schematic diagram of the pilot filtration unit with cleaning devices (BP-Backpulse and BWBackwash) used to treat the real OMW in different operation modes (Fraga et al., 2017) 


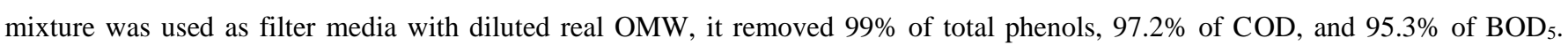
Interestingly, $\mathrm{Fe}_{2} \mathrm{O}_{3}$ /sand mixture has shown an excellent capacity to remove some OMW minerals, namely $\mathrm{Cr}^{+3}, \mathrm{Cu}^{+3}, \mathrm{~K}^{+}, \mathrm{Ca}^{+2}$, and $\mathrm{Na}^{+}$. This might indicate that $\mathrm{Fe}_{2} \mathrm{O}_{3}$ nanoparticles have multi-adsorption sites that can accommodate different contaminants, enhancing multilayer adsorption.

Vuppala et al., (2019) worked on optimizing coagulation and flocculation conditions for real OMW treatment, focusing on the effect of different $\mathrm{pH}$ and coagulant dosage values. System efficiency was checked at three various pH levels (4.5, 4.0, and 3.0), at a fixed dosage of two coagulants $-400 \mathrm{mg} / \mathrm{L}$ of aluminum sulfate (Alum), and $100 \mathrm{mg} / \mathrm{L}$ of chitosan. The top-performing $\mathrm{pH}=4.5 \mathrm{was}$ selected and kept constant for the optimization study of the coagulant dosage, alum, and chitosan, ranging from 400 to $1,200 \mathrm{mg} / \mathrm{L}$ of and 300 to $700 \mathrm{mg} / \mathrm{L}$, respectively. It was shown that 1 hour of sedimentation was enough to reach a $99 \%$ reduction of turbidity for both chitosan and alum. Among the tested coagulants, the study found that alum performance is better than chitosan, provided the process is operated at $\mathrm{pH}$ values $\geq 4.0$. The use of $800 \mathrm{mg} / \mathrm{L}$ of alum led to reductions of about $17 \%, 57 \%$, and $63 \%$ in TOC, COD, and phenols. A further decrease of $82 \%$ in COD, $72 \%$ in TOC, and $99 \%$ in phenols levels were achieved after the clarified water's biological oxidation treatment.

\subsection{Chemical treatment}

Researchers focused on electrohydrolysis and electrocoagulation, photocatalytic membrane reactor utilization, Fenton and Fentonlike processes, and hydrothermal carbonization among different available chemical treatment methods. Table $\mathbf{3}$ summarizes the reviewed chemical treatment methods, their targets/aims, and main results and findings. Hydrothermal carbonization (HTC) represents an efficient and valuable pre-treatment technology for wastes conversion into highly dense carbonaceous materials for various energetic, environmental, and agricultural applications. The use of the HTC process for the treatment of OMW has been recently investigated (Volpe et al., 2018; Azzaz et al., 2020). Olive waste stream mixture, coming from a three phase-continuous centrifugation olive oil mill, was subjected to HTC at 180,220 , and $250{ }^{\circ} \mathrm{C}$ for 3-h residence time in stainless steel electrically heated batch reactor (Volpe et al., 2018). Raw OMW and corresponding hydrochars were characterized. As HTC temperature increases, the hydrochars samples carbonization and energy densification ratio increase, with the latter reaching a maximum value of $142 \%$ at 250 ${ }^{\circ} \mathrm{C}$. The obtained hydrochars were pelletized using a lab-scale pelletizer without the addition of binders or densifying agents, and the one produced at $250{ }^{\circ} \mathrm{C}$ showed the best characteristics for palletization. Upon energy characterization (HHV, TGA), ATR-FTIR analysis, fouling index evaluation, and pelletization results, it was suggested that olive mill waste hydrochars could be used as energy-dense and mechanically stable biofuels. Characterization of HTC liquid fractions in terms of nutrients and polyphenolic compounds enabled us to evaluate their potential use as liquid fertilizers. Results showed that HTC could represent a greener alternative for the valorization of olive mill industry waste streams.

Similarly, HTC of OMW generated by three-phase mills was carried out using a high-pressure laboratory autoclave at three different temperatures 180,200 , and $220^{\circ} \mathrm{C}$ for 24-h residence time (Azzaz et al., 2020). Both solid and liquid produced from thermal conversion were analyzed. Results showed that solid (hydrochars) yield decreased from $57 \%$ to $25 \%$ when processing temperature was increased from $180{ }^{\circ} \mathrm{C}$ and $220^{\circ} \mathrm{C}$, while the fixed carbon percentage increased, accompanied by a decrease in ash and volatile matter percentages, suggesting that decarboxylation is the main reaction driving the HTC process. The O/C ratio decreased, allowing for an increase in the high heating value (HHV) by $32 \%$ for hydrochar prepared at $220^{\circ} \mathrm{C}$. On the other hand, organic contents, acids, alcohols, phenols, and sugar derivatives of process liquid were analyzed and high in concentrations and varied with carbonization temperatures. Upon considering the generated HTC products' physicochemical properties, they suggested using hydro chars in energy-related applications, while the liquid fraction could be beneficial in the agricultural field.

Ultra-pure hydrogen production via co-valorization of OMW and bioethanol in Pd-membrane reactors was presented by Alique et al., (2020). Fresh OMW was initially conditioned by filtration and distillation processes. The effect of pressure (1-5 bar), oxidizing conditions $\left(\mathrm{N}_{2}\right.$ or air as carrier gas), gas hourly space velocity $\left(150-1500 \mathrm{~h}^{-1}\right)$, and alcohol concentration on the co-reforming process $(5-10 \% \mathrm{v} / \mathrm{v})$ were studied. At the optimum conditions $\left(\mathrm{T}=450^{\circ} \mathrm{C}, \mathrm{P}=5.0\right.$ bar, feed: $15 \mathrm{~g} / \mathrm{h}$ mixture OMW-EtOH and $15 \mathrm{ml} / \mathrm{min} \mathrm{N}_{2}$, $10 \% \mathrm{v} / \mathrm{v} \mathrm{EtOH}$ concentration), $30 \mathrm{Nml} / \mathrm{min}$ of ultra-pure hydrogen was obtained.

Table 3 Summary of Reviewed Chemical Treatment Methods, their Target, and main Results and Findings

\begin{tabular}{llll}
\hline $\begin{array}{l}\text { Process } \\
\text { Target/Aim }\end{array}$ & Process & Results and Findings & Reference \\
& & Optimum conditions: nano-ZnO-Magnetite concentration \\
of $3 \mathrm{~g} / \mathrm{L}$, the irradiation time of 30 minutes, and the $\mathrm{pH}$ & Sponza and \\
$\begin{array}{l}\text { Removal of } \\
\text { pollutants }\end{array}$ & $\begin{array}{l}\text { Photocatalytic degradation by nano- } \\
\text { ZnO-Magnetite composite }\end{array}$ & $\begin{array}{l}\text { At these conditions, COD, total phenol, TS, total nitrogen, } \\
\text { and total phosphorus removal efficiencies were } 80 \%,\end{array}$ & Balaban. 2018
\end{tabular}


$75 \%, 70 \%, 97 \%$, and $85 \%$, respectively.

Using response surface methodology (RSM), optimum conditions were reached at current density of $21.1 \mathrm{~mA} /$ Electrocoagulation (EC)

Electrocoagulation (EC) using aluminum and iron electrodes in the laboratory- and pilot-scale reactors

Electrocoagulation (EC) using aluminum electrode reactor $s$ in the laboratory- and pilot-scale reactors

Electrocoagulation (EC) powered by the photovoltaic solar system using two aluminum electrodes

Fenton process and ozone/Fenton combined process

Removal of

Electrohydrolysis (EH) using two parallel aluminum electrodes

pollutants and hydrogen production

Valorization of olive mill industry waste streams

Pd-membrane reactors

Plasma technology

Removal of organic content

Removal of phenolic

$\mathrm{cm}^{2}$ and $58.9 \mathrm{~min}$ of EC time. The highest removal

efficiency for $\mathrm{TPh}$, approximately $83 \%$, was obtained.

This prediction agreed with the laboratory result $(83.5 \%)$.

Aluminum electrodes were found to be more efficient than iron electrodes

In the pilot-scale reactor, optimum results were attained at a current density of $5.65 \mathrm{~mA} / \mathrm{cm}^{2}$, with $42.5 \%$ COD and

$85.3 \%$ color removal from biologically pre-treated TOPW.

Under the optimum conditions of $2 \mathrm{~h}$ electrolysis time, $41.6 \mathrm{~mA} / \mathrm{cm}^{2}$ current density, and $2 \mathrm{~g} / \mathrm{L}$ of added salt, the discoloration of OMW diluted ten times is around $91 \%$, and the reduction of the COD is $50 \%$.

Removal of $~ 79 \%$ COD, $95 \%$ polyphenols, and $98 \%$ dark color within $40 \mathrm{~min}$ of treatment at $32.14 \mathrm{~mA} / \mathrm{cm}^{2} \mathrm{CD}$, 5.6 initial $\mathrm{pH}$, and electrodes positioned $35 \mathrm{~cm}$ from the bottom of the riser compartment.

With Fenton only process, high color (51.6\%), CODs (58\%), DOC (27.9\%) and phenol (93.9\%) removals were achieved with $10 \mathrm{H}_{2} \mathrm{O}_{2} / \mathrm{Fe}^{2+}$ molar ratio.

The combined ozone/Fenton process at the same optimum conditions enhanced treatment performance by $21 \%$, $49 \%$, and $22 \%$ in color, DOC, and CODs removals.

After 24 hours of EH treated OMW settling, 75\% COD, $56 \%$ soluble COD, $93 \%$ turbidity, $61 \%$ total solids (TS), 94\% TSS, and $92 \%$ color removal efficiencies were determined. After $6 \mathrm{~h}$ of EH, $1500 \pm 50 \mathrm{ml}$ gas was produced, and $88 \%$ hydrogen content of gas was obtained.

After $8 \mathrm{~h}$ reaction time at an electric potential gradient of $8 \mathrm{~V}, 73 \%$ total COD, $84 \%$ suspended solids, $91 \%$ color, and $75 \%$ phenol removal efficiencies were attained.

aluminum electrodes,

At the end of the operating period of $8 \mathrm{~h}, 1037 \mathrm{ml}$ of hydrogen gas was obtained.

Hydrochars with high carbonization and energy densification ratio.

Hydrothermal carbonization (HTC)

Hydrothermal carbonization (HTC)

HTC liquid fractions, rich in nutrients and polyphenolic compounds, can be used as liquid fertilizers.

The hydrochars high heating value (HHV) increases with increasing process temperature, while its solid yield decreases.

Liquid Physico-chemical properties suggest using it in the agricultural field

At the optimum conditions $\left(\mathrm{T}=450^{\circ} \mathrm{C}, \mathrm{P}=5.0 \mathrm{bar}\right.$, feed: $15 \mathrm{~g} / \mathrm{h}$ mixture OMW-EtOH and $15 \mathrm{ml} / \mathrm{min} \mathrm{N}_{2}, 10 \% \mathrm{v} / \mathrm{v}$ EtOH concentration), $30 \mathrm{Nml} / \mathrm{min}$ of ultra-pure hydrogen was obtained.

COD and BOD of olive mill wastewater are decreased by $94.4 \%$ and $95.4 \%$, respectively.

Dissolved oxygen amount increased from 0.36 to 6.97 $\mathrm{mg} / \mathrm{L}$.

Plasma gas with high $\mathrm{H}_{2}$ content $\left(60-75 \% \mathrm{H}_{2}, 4-10 \%\right.$

$\mathrm{CO}_{2}, 1-2 \% \mathrm{CO}$, and $14-18 \% \mathrm{O}_{2}$ ) was obtained.

high removals of COD (89\%), TOC (87\%), and phenolic compounds (95\%) at $20 \mathrm{~min}$ of operation.

Sulfate and hydroxyl radicals were responsible for TSL

Niazmand et al., 2020

Benekos et al., 2019

Yassine et al., 2018

Elkacmi et al., 2020

Kirmaci et al.,

2018

Erdem et al., 2016

Ayman $\mathrm{Oz} \&$

Eker. 2019

Volpe et al., 2018

Azzaz et al., 2020

Alique et al., 2020

Ibrahimoglu et al., 2018

Fraga et al., 2019 Silicon carbide membranes with their surfaces being modified with $\mathrm{TiO}_{2}$

Photochemical degradation of tyrosol (TSL) by UV-254 nm 
compounds irradiated common oxidants

OMW pre-

treatment
Acid flocculation followed by photocatalytic membrane degradation.

Degradation of TSL followed pseudo-first-order kinetics

The highest TOC removal ( $35 \%$ ) was achieved by UV/ persulfate treatment.

Acid flocculation fully satisfies the requirements and can be adopted as a stand-alone pre-treatment process

Stoller et al., 2017 $59 \%$, but it is unreasonable economically, as it doubles the cost.

Another valorization technique produced plasma gas with high $\mathrm{H}_{2}$ content (Ibrahimoglu et al., 2018). Plasma technology was used to reduce pollution parameters in OMW and draw water to discharge limits. COD and BOD of olive mill wastewater are decreased by $94.4 \%$ and $95.4 \%$, respectively. The dissolved oxygen amount increased from 0.36 to $6.97 \mathrm{mg} / \mathrm{L}$. Besides the disposal, plasma gas with high $\mathrm{H}_{2}$ content $\left(60-75 \% \mathrm{H}_{2}, 4-10 \% \mathrm{CO}_{2}, 1-2 \% \mathrm{CO}\right.$, and $\left.14-18 \% \mathrm{O}_{2}\right)$ was obtained. The treated water was tested and found that it can be used in agricultural areas for irrigation, as its SAR (Sodium Adsorption Ratio) value was found to be 1.14.

Membrane processes appear to be suitable to purify OMW from organic matter and other pollutants but suffer severe fouling. Stoller et al., (2017) discussed the technical and economic benefits of using photocatalysis as a pre-treatment step for OMW treatment process by membranes. They treated 2-phase and 3-phase OMW through $\mathrm{HNO}_{3}$ acid flocculation by (AF), and photocatalysis using titania nanoparticles (PC). They found that photocatalysis as an additional pre-treatment process appears to be beneficial from a technical point of view, as it increased the plant productivity by $18 \%-59 \%$. On the other hand, photocatalysis as an additional pretreatment process is not economically reasonable since costs are doubled. Acid flocculation appears to satisfy the requirements fully and should be adopted as a stand-alone pre-treatment process for this kind of wastewater.

OMW photocatalytic degradation was also investigated by Sponza and Balaban (2018). They treated raw OMW taken from the olive mill industry by nano-ZnO-Magnetite composite via adsorption and photocatalytic degradation. They found that for photocatalytic degradation under UV, the optimum conditions were nano-ZnO-Magnetite concentration of $3 \mathrm{~g} / \mathrm{L}$, the irradiation time of 30 minutes, and $\mathrm{pH}$ value of 4 . At these conditions, COD, total phenol, TS, total nitrogen, and total phosphorus removal efficiencies were $80 \%$, $75 \%, 70 \%, 97 \%$, and $85 \%$, respectively.

Fraga et al., (2019) developed a new design of a photocatalytic membrane reactor and tested it for treating real OMW and enhancing its organic compounds' degradation. The reactor has a cuboid shape with a squared base and is made of polyethylene. Commercial high flux flat sheet silicon carbide membranes are used, and their surfaces were modified with $\mathrm{TiO}_{2}$ obtained by the sol-gel process, using Degussa P25 and silicon carbide nanoparticles. Results proved the photocatalytic activity of the membrane, achieving high removals of chemical oxygen demand (89\%), total organic carbon (87\%), and phenolic compounds (95\%) with this system at 20 min of operation. The high particulates concentration in OMW causes cake formation on the membrane surface that prevents light from reaching the membrane's photocatalytic layer, leading to a reduction of the produced permeate quality. They suggested solving this problem in a pilot/full-scale system through effective pre-treatment and applying previously proven strategies to minimize fouling, such as backwashing and back pulsing, Fraga et al., (2017).

Kirmaci et al., (2018) investigated the Fenton process, and ozone/Fenton combined process applicability to remove color, soluble CODs, phenol, and dissolved organic carbon (DOC) from real OMW. Two $\mathrm{H}_{2} \mathrm{O}_{2} / \mathrm{Fe}^{2+}$ molar ratios (10 and 20) with $0.5 \quad \mathrm{mM} \quad \mathrm{H}_{2} \mathrm{O}_{2}$ concentration were used to optimize the Fenton process. High color (51.6\%), CODs (58\%), DOC (27.9\%) and phenol (93.9\%) removals were achieved with the $10 \mathrm{H}_{2} \mathrm{O}_{2} / \mathrm{Fe}^{2+}$ molar ratio. Compared to the only-Fenton process, when combined ozone/Fenton process (Figure 3) was employed at these optimum conditions, OMW's enhanced treatment performance by $21 \%, 49 \%$, and $22 \%$ in terms of color, DOC, and CODs removals, respectively, was observed. The treatment performance was significantly affected by ozonation time, and the optimum reaction

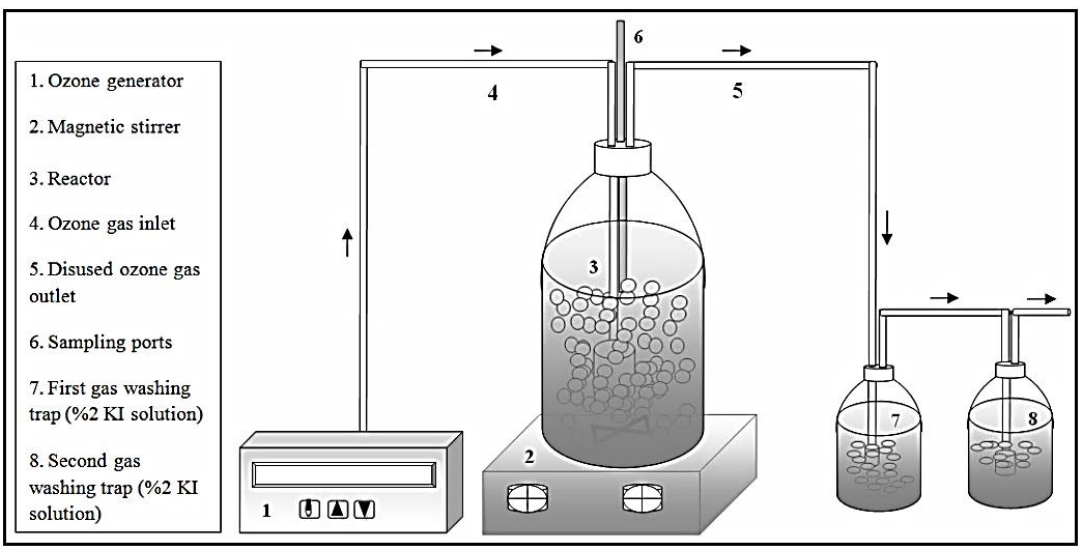

Fig. 3 Schematic diagram of lab-scale combined ozone/Fenton process (Kirmaci et al., 2018) 
time was determined to be 90 minutes. Ozonation combined with bio-treatment can convert the nonbiodegradable and hard-tobiodegrade compounds into readily biodegradable compounds for the bio-treatment, resulting in a safer effluent disposal environment.

Kilic et al., (2019) studied the photochemical degradation and mineralization of tyrosol (TSL), a model phenolic compound present in OMW, by UV-254 nm irradiated common oxidants: peroxymonosulfate (PMS), hydrogen peroxide $\left(\mathrm{H}_{2} \mathrm{O}_{2}\right)$, and persulfate (PS). The photogenerated radicals in the degradation systems were quantified by using probe methods. Results revealed that sulfate and hydroxyl radicals were responsible for TSL degradation and mineralization, with $\mathrm{SO}_{4}{ }^{-{ }^{-}}$being the dominant species in UV/PS and UV/PMS systems. Under all experimental conditions examined in the study, degradation of TSL followed pseudo-first-order kinetics, with the efficiencies following the order of UV/PS $>\mathrm{UV} / \mathrm{H}_{2} \mathrm{O}_{2}>\mathrm{UV} / \mathrm{PMS}$. The better removal of TSL by UV/PS AOP compared to other systems was correlated with its high quantum yield and the higher concentration of sulfate radicals in the system. The effects of phosphate buffer concentrations and the presence of inorganic anions (i.e., $\mathrm{Cl}-$, SO42- and NO3-) were also investigated and found to have a limited impact on all degradation systems tested. On the other hand, inorganic ions decreased the TOC removal for both UV/PMS and UV/H2O2 processes significantly. Among the three processes, UV/PS was the least affected by inorganic ions and achieved the highest TOC removal $(\sim 35 \%)$. For all degradation systems, the removal efficiency of TSL was slightly higher in an acidic medium ( $\mathrm{pH}=4.0$ ). Overall, UV/PS system showed faster degradation kinetics than $\mathrm{UV} / \mathrm{H}_{2} \mathrm{O}_{2}$ and UV/PMS for the degradation and mineralization of TSL. Investigation of degradation byproducts and the treated water's biotoxicity is needed for a more comprehensive estimation of the treatment efficiency. In recent years, electrohydrolysis (EH) and electrocoagulation (EC) processes have attracted increasing interest as promising methods because of their simple equipment, easy operation, environmental compatibility, low capital cost, and capacity to remove a wide variety of pollutants present in wastewaters and reduction in sludge amount. Electrohydrolysis $(\mathrm{EH})$ has an added advantage as it produces hydrogen energy from different waste/wastewaters with high organic content.

Erdem et al., (2016) assessed the effectiveness of OMW electrohydrolysis using a lab-scale $1 \mathrm{~L}$ glass reactor in removing pollutants and producing hydrogen. Electrohydrolysis process was performed with $600 \mathrm{ml}$ raw OMW sample volume, using two parallel aluminum electrodes and $10 \mathrm{~V}$ DC power supply for six hours. After 24 hours of settling, 75\% COD, 56\% soluble COD, 93\% turbidity, $61 \%$ total solids (TS), 94\% TSS, and 92\% color removal efficiencies were determined in the supernatant. At the end of the electrohydrolysis period of $6 \mathrm{~h}, 1500 \pm 50 \mathrm{ml}$ gas was produced, and $88 \%$ hydrogen content was obtained.

Ayman $\mathrm{Oz}$ and Eker (2019) investigated the electrohydrolysis (EH) process, using aluminum electrodes, to remove organic compounds, detoxification, and discoloration of OMW, with simultaneous energy production in the hydrogen gas form. Overall results showed that the process is beneficial for color and turbidity parameters. The most effective conditions for removing pollutants were determined as $8 \mathrm{~h}$ reaction time and electric potential gradient of $8 \mathrm{~V}$. Under these conditions, 73\% total COD, 84\% suspended solids, $91 \%$ color, and $75 \%$ phenol removal efficiencies were attained. Also, at the end of the operating period of $8 \mathrm{~h}$, $1037 \mathrm{ml}$ of hydrogen gas was obtained. The process is claimed to be a suitable alternative for hydrogen production from wastewater streams and existing treatment options or an additional pre-treatment step in managing the effluents from the olive mill industry. Process performance can be upgraded, and discharge standards can be met by improving the reactor design or by combining the process with other treatment processes. Niazmand et al., (2020) investigated the optimization of electrocoagulation (EC) conditions for the olive debittering wastewater (ODW) purification by response surface methodology (RSM). To optimize the process, a central composite design (CCD) was applied with variables including EC time $(10.0-60.0 \mathrm{~min})$ and current density $\left(3.0-30.0 \mathrm{~mA} / \mathrm{cm}^{2}\right)$. The results indicated a noticeable effect of current density and EC time on the efficiency of total phenolic compounds (TPCs) and COD removal. They reached optimum conditions at a current density of $21.1 \mathrm{~mA} / \mathrm{cm}^{2}$ and $58.9 \mathrm{~min}$ of EC time, at which the highest removal efficiency for TPCs, approximately $83 \%$, were obtained. Figure 4 shows the laboratory set-up used to verify the theoretical finding, in which $83.5 \%$ TPCs removal was attained.

Experimentally, Benekos et al., (2019) investigated electrocoagulation (EC) for table olive processing wastewater (TOPW) treatment using different current densities and initial COD concentrations. Using aluminum and iron electrodes, experiments were performed in both laboratory- and pilot-scale reactors to determine the EC efficiency as a single treatment process or as a post-treatment step, respectively. In both laboratory and pilot-scale experiments, aluminum electrodes were found to be more efficient in reducing COD and color than iron electrodes, as well as in metal and energy consumptions. In the pilot-scale reactor, optimum results were attained at a current density of $5.65 \mathrm{~mA} / \mathrm{cm}^{2}$, with $42.5 \%$ COD and $85.3 \%$ color removal from biologically pre-treated TOPW.

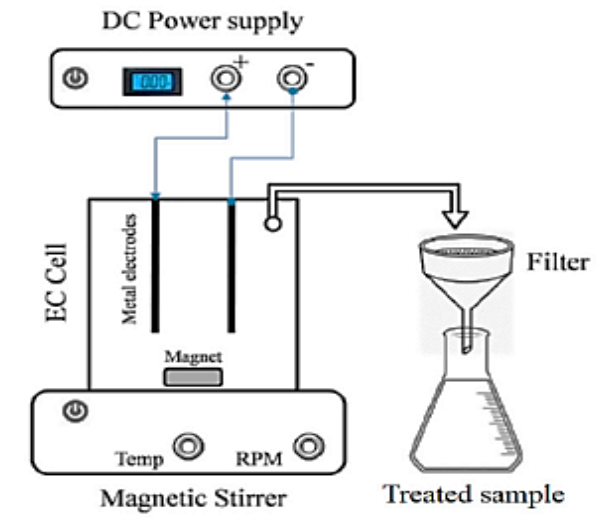

Fig. 4 The electrocoagulation-filtration set-up used in the laboratory analysis. (Niazmand et al., 2020) 
Electrocoagulation is an aluminum electrode reactor is also used to treat OMW collected from a traditional oil mill (Yassine et al., 2018). It was found that increasing electrolysis time and current intensity significantly enhance the treatment performance but also increase electrode metal and energy consumptions. Study results showed that under the optimum conditions of $2 \mathrm{~h}$ electrolysis time, the current density of $41.6 \mathrm{~mA} / \mathrm{cm}^{2}$, and added salt of $2 \mathrm{~g} / \mathrm{L}$, the discoloration of the OMW diluted ten times is around $91 \%$, and the reduction of the COD is $50 \%$ leading to decrease of OMW pollutant power.

Elkacmi et al., (2020) investigated the detoxification of OMW in an external loop airlift reactor (ALR) by electrocoagulation (EC) powered by a photovoltaic solar system as a renewable and sustainable energy source. A continuous flow with two aluminum electrodes was used to study the effect of operating parameters such as initial $\mathrm{pH}$, electrolysis time, current density (CD), and the electrode's axial position. The results showed removal of about $79 \%$ of COD, $95 \%$ of polyphenols, and $98 \%$ of dark color within 40 min of treatment at $32.14 \mathrm{~mA} / \mathrm{cm}^{2} \mathrm{CD}, 5.6$ initial $\mathrm{pH}$, and electrodes positioned $35 \mathrm{~cm}$ from the bottom of the riser compartment. Electrical energy consumption and electrode consumption were found to be $9.86 \mathrm{kWh} / \mathrm{m}^{3}$ and $0.1118 \mathrm{~kg} / \mathrm{m}^{3}$, respectively. Consequently, these obtained results under optimal conditions revealed that coupling the electrocoagulation process with a photovoltaic solar system in a continuous airlift reactor offers a low operation cost compared to other treatment processes.

\subsection{Integrated treatments}

To achieve acceptable wastewaters that can be readily discharged to the environmental water bodies, many researchers investigated integrated systems, in which more than one treatment method is used in series. Table 4 summarizes the reviewed integrated treatment methods, their targets/aims, and main results and findings. Amaral-Silva et al., (2016) applied integrated coagulation/flocculation and Fenton processes to OMW treatment. They showed that coupling the coagulation stage with flocculation promotes greater removal efficiency than single coagulation for higher organic matter removal by gravitational settling. The highest COD removal was attained when $0.1 \mathrm{~g} / \mathrm{L}$ of $2045-\mathrm{SH}$ flocculant was applied to wastewater previously treated with $1 \mathrm{~g} / \mathrm{L}$ of P19 coagulant, leading to $82 \%$ elimination and $84 \%$ abatement of total polyphenolic content (TPh). A further combination with the Fenton process revealed that it is possible to reach larger COD and TPh content abatement (90\% and 92\%) and a biodegradability enhancement to 0.52 compared to the 0.05 of the raw OMW. They studied the main parameters that can affect this system: operating $\mathrm{pH}, \mathrm{Fe}^{2+}$ and $\mathrm{H}_{2} \mathrm{O}_{2}$ concentrations, and the ratio between them. An improvement in the pollutants' degradation is observed with higher $\mathrm{H}_{2} \mathrm{O}_{2}$ levels and higher $\mathrm{H}_{2} \mathrm{O}_{2} / \mathrm{Fe}^{2+}$ ratio until a plateau is reached. Also, increasing iron load, up to a certain level, permits a better COD removal, after which higher iron concentration promotes an adverse effect on the performance rate, possibly due to the $\mathrm{Fe}^{2+}$-induced radical scavenging. The treated stream TSSs and TDSs decreased by $95 \%$ and $69 \%$, respectively.

Interestingly, they observed that a higher amount of hydrogen peroxide for the same iron dose promotes less biodegradable treated wastewater; lower $\mathrm{BOD}_{5} / \mathrm{COD}$ ratio. They also noticed that adding hydrogen peroxide to the Fenton reactor intermittently reduces the $\mathrm{H} 2 \mathrm{O} 2$ scavenger effect toward hydroxyl radicals. Its concentration is maintained at a low level reducing the oxidant waste during the treatment and promoting a higher oxidation rate and efficiency. They also showed that the pre-adjustment of $\mathrm{pH}$ and its maintenance within the selected range $(3.0 \pm 0.1)$ enhanced the COD and TPh removal rates by Fenton oxidation. The integrated coagulationoxidation system presents a process in which $92.6 \% \mathrm{COD}$ and $98.3 \%$. TPh removals are attained. Besides, $\mathrm{BOD}_{5} / \mathrm{COD}$ ratio was improved from 0.05 to 0.39 .

On a similar aspect, Esteves et al., (2019) treated undiluted highly-loaded OMW $\left(\mathrm{TOC}_{0}=8.5 \mathrm{~g} / \mathrm{L}\right.$ and COD $024.4 \mathrm{~g} / \mathrm{L}$, both after sedimentation), coming from the operation of a three-phase olive mill, using. For the Fenton-like system $\left(\mathrm{Fe}^{3+} / \mathrm{H}_{2} \mathrm{O}_{2}\right)$, they found that the gradual addition of $\mathrm{H}_{2} \mathrm{O}_{2}$ along with $\mathrm{pH}$ readjustments during the process leads to better COD and TPh reduction and enhanced TOC degradation rate, especially in earlier stages of the reaction. On the other hand, the reagents addition method does not affect the overall extent of TOC removal. When operating at initial conditions of $\mathrm{pH}=3.0, \mathrm{~T}=25^{\circ} \mathrm{C},\left[\mathrm{Fe}^{3+}\right]=1.0 \mathrm{~g} \cdot \mathrm{L}^{-1}$ and $\mathrm{Fe} / \mathrm{H}_{2} \mathrm{O}_{2}=0.04$, removal of $34.9 \%$ TOC, $55.7 \% \mathrm{COD}$ and $81.4 \% \mathrm{TPh}$ were attained after $180 \mathrm{~min}$. Radiation filtration by OMW dark color and high turbidity hindered significant improvements in photo-Fenton-like process efficiency $(41.8 \%$ of TOC, 63.2\% of COD, and $83.8 \%$ of $\mathrm{TPh}$ removals under the same conditions).

In comparison with the classic Fenton process $\left(\mathrm{Fe}^{2+} / \mathrm{H}_{2} \mathrm{O}_{2}\right)$, they found that the extent of TOC removal is greater with Fenton-like oxidation $\left(\mathrm{Fe}^{3+} / \mathrm{H}_{2} \mathrm{O}_{2}\right)$. At the same time, the degradation rate is higher for the classic process. Ferric chloride acted in the Fenton-like process both as catalyst and coagulant/flocculant. After the oxidation process, one hour of sedimentation allowed for 76.7\% COD and 96.4\% TPh global reductions in the investigated system. Moreover, this combined process improved the effluent's biodegradability $\left(\mathrm{BOD}_{5}: \mathrm{COD}\right.$ ratio) from the initial value of 0.11 to 0.33 , and decreased toxicity against the bioluminescent Vibrio fischeri bacteria from $53 \%$ to $4 \%$. 
Table 4 Summary of Reviewed Integrated Treatment Methods, Target, and main Results and Findings.

\begin{tabular}{|c|c|c|c|}
\hline \multirow{2}{*}{$\begin{array}{l}\text { Process } \\
\text { Target/Aim }\end{array}$} & Process & Results and Findings & Reference \\
\hline & $\begin{array}{l}\text { Integrated } \\
\text { coagulation/flocculation and } \\
\text { Fenton processes }\end{array}$ & $\begin{array}{l}\text { The highest COD removal }(82 \%) \text { was attained when } 0.1 \mathrm{~g} / \mathrm{L} \text { of } \\
2045-\mathrm{SH} \text { flocculant was applied to wastewater previously treated } \\
\text { with } 1 \mathrm{~g} / \mathrm{L} \text { of P19 coagulant, leading to } 84 \% \text { abatement of } \mathrm{TPh} \\
\text { content. A further combination with the Fenton process allowed } \\
\text { reaching larger COD and TPh content abatement ( } 90 \% \text { and } 92 \%) \\
\text { and a biodegradability enhancement to } 0.52 \text { compared to the } 0.05 \\
\text { of the raw OMW. } \\
\text { The integrated coagulation-oxidation system allows attaining } \\
92.6 \% \text { COD and } 98.3 \% \text { TPh removals. } \\
\text { For the Fenton-like, the gradual addition of } \mathrm{H}_{2} \mathrm{O}_{2} \text { and pH } \\
\text { readjustments during the process lead to better COD and TPh } \\
\text { reduction and TOC degradation rate. Ferric chloride acted in the } \\
\text { Fenton-like process both as catalyst and coagulant/flocculant. } \\
\text { One hour of sedimentation after the oxidation process allowed for } \\
76.7 \% \text { COD and } 96.4 \% \text { TPh global reductions in the investigated } \\
\text { system and improved the effluent's biodegradability from the } \\
\text { initial value of } 0.11 \text { to } 0.33 \text {. }\end{array}$ & $\begin{array}{l}\text { Amaral-Silva et } \\
\text { al., } 2016\end{array}$ \\
\hline \multirow{4}{*}{$\begin{array}{l}\text { Removal of } \\
\text { pollutants, reduce } \\
\text { organic load and } \\
\text { improve the } \\
\text { biodegradability }\end{array}$} & $\begin{array}{l}\text { The combination of } \\
\text { electrocoagulation (using Fe } \\
\text { electrodes), catalytic } \\
\text { ozonation, and } \\
\text { biodegradation }\end{array}$ & $\begin{array}{l}\text { Optimal conditions for the electrocoagulation process are at } 5 \\
\mathrm{~mA} / \mathrm{cm}^{2} \mathrm{CD} \text { for } 45 \text { min reaction time. } \\
\text { The combined system's overall efficiency in removing COD and } \\
\text { TOC was } 98.4 \% \text { and } 97.2 \% \text {, respectively. }\end{array}$ & $\begin{array}{l}\text { Khani et al., } \\
2020\end{array}$ \\
\hline & $\begin{array}{l}\text { Coagulation/flocculation } \\
\text { with electrolytes and } \\
\text { polyelectrolytes }\end{array}$ & $\begin{array}{l}\text { Among the screened electrolytes, } \mathrm{FeCl}_{3} \text { was the most effective one } \\
\text { in terms of COD reduction }(43 \%) \text {, and PDA DMAC was the most } \\
\text { effective polyelectrolytes }(46 \% \mathrm{COD} \text { reduction). } \\
\text { The best results were obtained when } 20 \mathrm{~g} / \mathrm{L} \text { of } \mathrm{Ca}(\mathrm{OH})_{2} \text { as an } \\
\text { electrolyte was combined with PDADMAC polyelectrolyte at } 1.25 \\
\mathrm{~g} / \mathrm{L} \text { : reductions of } 43 \% \text { in TS, } 27 \% \text { in TSS, } 56 \% \text { in COD, and } \\
76 \% \text { in phenols. }\end{array}$ & $\begin{array}{l}\text { Iakovides et al., } \\
2016\end{array}$ \\
\hline & $\begin{array}{l}\text { Flocculation, photolysis and } \\
\text { microfiltration, integrated } \\
\text { with microalgal growth } \\
\text { stages }\end{array}$ & $\begin{array}{l}\text { Physico-chemical treatments allowed for a significant reduction of } \\
\text { OMW organic load. } \\
\text { The final treated water is claimed to be suitable for irrigation use, } \\
\text { discharge to receiving waters, or reuse in the process itself, } \\
\text { allowing it to close the process water cycle. }\end{array}$ & $\begin{array}{l}\text { Malvis et al., } \\
2019\end{array}$ \\
\hline & Integrated two-stage process & $\begin{array}{l}\text { First stage: pre-ozonation, primary sediment separation, } \\
\text { electrocoagulation and lime suspension treatment. In the first } \\
\text { stage, } 59 \% \text { of COD, } 86 \% \text { of total phenols, } 70 \% \text { of color and } 91 \% \\
\text { of TS reduction was attained. } \\
\text { Second stage: pre-ozonation reactor, oxidation process using } \\
\left(\left(\mathrm{Fe}_{2} \mathrm{O}_{3}+\mathrm{CuO}\right) / \mathrm{Clay}\right) \text { catalytic system, followed by adsorption on } \\
\text { charcoal. In the second stage, } 96 \% \text { of COD, } 100 \% \text { of total phenols } \\
\text { and color and TSS reduction was attained. }\end{array}$ & $\begin{array}{l}\text { Jomaa and } \\
\text { Hourieh. } 2020\end{array}$ \\
\hline
\end{tabular}

Khani et al., (2020) studied the combination of electrocoagulation, catalytic ozonation, and biodegradation to reduce organic load and improve OMW's biodegradability. Electrocoagulation was performed using Fe electrodes at a current density of 7.3, 5, and 0.5 $\mathrm{mA} / \mathrm{cm}^{2}$. The electrocoagulation process's optimal conditions are found to be at $5 \mathrm{~mA} / \mathrm{cm}^{2} \mathrm{CD}$ for 45 min reaction time. The treated wastewater under these optimal conditions was then fed to a catalytic ozonation process (COP) reactor (Figure 5). In the COP, 44\% TOC and 56\% COD removals were achieved after $90 \mathrm{~min}$. Eventually, the COP reactor effluent was introduced into the biological reactor. The combined system's overall efficiency in removing COD and TOC was $98.4 \%$ and 97.2\%, respectively. 


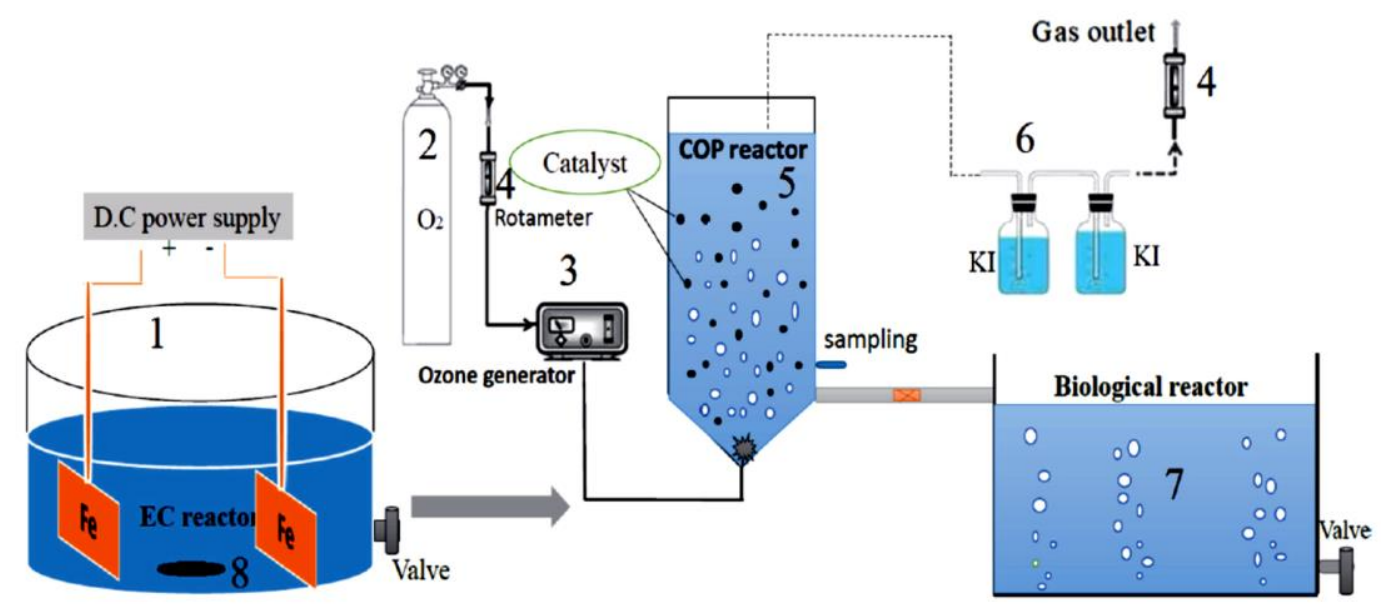

Fig. 5 Schematic diagram of olive oil wastewater treatment processes; 1. Electrocoagulation cell, 2. Oxygen capsule, 3. Ozone generator, 4. Rotameter, 5.COP reactor, 6. Gas trapper, 7. Biological reactor, 8. Magnetic mixer (Khani et al., 2020)

Iakovides et al., (2016) presented experiments of coagulation/flocculation with electrolytes $\left[\mathrm{FeCl}_{3}, \mathrm{Ca}(\mathrm{OH})_{2}, \mathrm{CaO} \mathrm{CaCl}_{2}\right]$ and polyelectrolytes (PDADMAC, PAH, PAA, PEI, Floccan 22-23) as a physicochemical method for the OMW treatment. They focused on decreasing the suspended particles' electrical charge by monitoring the changes in the zeta potential of the particles. Among the screened electrolytes, $\mathrm{FeCl}_{3}$ was the most effective in terms of COD reduction (43\%). On the other hand, PDADMAC was the most effective polyelectrolytes (46\% COD reduction). Moreover, they identified the isoelectric point through zeta potential measurement, and it coincided with the coagulant concentration that caused optimum organic load reduction percentages. The best results were obtained when $20 \mathrm{~g} / \mathrm{L}$ of $\mathrm{Ca}(\mathrm{OH})_{2}$ as an electrolyte was combined with PDADMAC polyelectrolyte at $1.25 \mathrm{~g} / \mathrm{L}$, where reductions of $43 \%$ in TS, $27 \%$ in TSS, $56 \%$ in COD, and $76 \%$ in phenols were observed.

Malvis et al., (2019) proposed an integral process based on Physico-chemical (flocculation, photolysis, and microfiltration) and microalgal growth stages for the treatment of real OMW obtained from an olive oil extraction plant. The primary treatment (flocculation-sedimentation, photolysis and microfiltration) allowed for significant reduction of OMW organic load (96.2\% of COD, $80.3 \%$ of TOC and $96.6 \%$ of total phenolic compounds (TPCs)). Secondary treatment eliminated the rest of OMW organic load. In the secondary treatment, they conducted different experiments using the microalgae Chlorella pyrenoidosa on a laboratory scale in stirred batch tank reactors at different OMW concentrations in the culture medium: 5\%, 10\%, 25\%, 50\%, 75\%, and 100\% (v/v). The $50 \%(\mathrm{v} / \mathrm{v})$ was found to be the optimum OMW concentration at which the highest maximum specific growth rate $\left(\mu_{\mathrm{m}}=0.07 \mathrm{~h}^{-1}\right)$ and volumetric biomass production $\left(\mathrm{P}_{\mathrm{b}}=1.25 \mathrm{mg} /(\mathrm{L} . \mathrm{h})\right)$ were achieved. They claimed the final treated water to be suitable for irrigation use, discharge to receiving waters, or reuse in the process itself, allowing them to close the process water cycle.

Jomaa and Hourieh (2020) used an integrated two-stage process to treat OMW under atmospheric pressure and room temperature. They reduced $59 \%$ of COD, $86 \%$ of total phenols, $70 \%$ of color, and $91 \%$ of TS in the first stage, including pre-ozonation of raw OMW, primary sediment separation, followed by electrocoagulation, and lime suspension treatment. In the second stage, treated OMW was driven to a pre-ozonation reactor followed by an oxidation process using $\left(\left(\mathrm{Fe}_{2} \mathrm{O}_{3}+\mathrm{CuO}\right) / \mathrm{Clay}\right)$ catalytic system at 25 min residence time by adsorption on charcoal. This stage reduced $96 \%$ of COD, $100 \%$ of total phenols, and color and TSS.

\section{Conclusions}

From the literature reviewed herein, it can be concluded that there is no ideal olive mill wastewater (OMW) treatment solution. Several environmentally friendly and economically viable solutions are presented and proposed, including physical, chemical, and integrated treatment methods. No one method is suitable for all types of OMWs, as they differ from one region to another in their chemical and physical properties and characteristics. Although OMWs is currently considered waste, it can become a valuable energy source and high value-added natural products. Future research should explore various treatment methods and combine different approaches to utilize the most appropriate and economically feasible process.

\section{Nomenclature}

AOP $\quad=$ advanced oxidation process

ATR-FTIR: =Attenuated total reflectance-Fourier transform infrared spectroscopy

BET =Brunauer-Emmett-Teller 


\begin{tabular}{|c|c|}
\hline BOD & $=$ biochemical oxygen demand \\
\hline $\mathrm{CD}$ & $=$ current density \\
\hline COD & $=$ Chemical Oxygen Demand \\
\hline DOC & $=$ dissolved organic carbon \\
\hline EC & $=$ electrocoagulation \\
\hline EDX & $=$ energy-dispersive $\mathrm{X}$-ray \\
\hline $\mathrm{EH}$ & $=$ electrohydrolysis \\
\hline FTIR & $=$ Fourier transform infrared spectroscopy \\
\hline GAC & $=$ Granular Activated Carbons \\
\hline GAC-OX & =oxidized Granular Activated Carbons \\
\hline $\mathrm{HHV}$ & $=$ high heating value \\
\hline HTC & =Hydrothermal carbonization \\
\hline MSL & $=$ multi-soil-layering \\
\hline Mt & $=$ montmorillonite \\
\hline NF & $=$ nanofiltration \\
\hline OMW & $=$ Olive Mill Wastewater \\
\hline PMS & $=$ peroxymonosulfate \\
\hline $\mathrm{RO}$ & $=$ reverse osmosis \\
\hline SEM & $=$ scanning electron microscope \\
\hline SPN & $=$ Quillaja saponins \\
\hline TBAB & $=$ tetra butyl ammonium bromide \\
\hline TDS & $=$ total dissolved solids \\
\hline TGA/DTA & $=$ thermal gas analysis \\
\hline TOPW & $=$ table olive processing wastewater \\
\hline TPCs & $=$ total phenolic compounds \\
\hline $\mathrm{TPh}$ & $=$ total phenolic content \\
\hline TS & $=$ total solids \\
\hline TSL & $=$ tyrosol \\
\hline TSS & $=$ total suspended solids \\
\hline UF & $=$ ultrafiltration \\
\hline XRD & $=\mathrm{X}$-ray Diffraction \\
\hline $\mathrm{XRF}$ & $=\mathrm{X}$-ray fluorescence \\
\hline
\end{tabular}

\section{References}

Abu-Lafi, S., Al-Natsheh, M. S., Yaghmoor, R., and Al-Rimawi F. "Enrichment of Phenolic Compounds from Olive Mill Wastewater and In Vitro Evaluation of Their Antimicrobial Activities", Evidence-Based Complementary and Alternative Medicine, 2017, 1-9 (2017).

Ait-hmane, A., Ouazzani, N., Latrach, L., Hejjaj, A., Assabbane, A., Belkouadssi, M., and Mandi L. "Feasibility of Olive Mill Wastewater treatment by MultiSoil-Layering Ecotechnology”, J. Mater. Environ. Sci., 9, 1223-1233 (2018).

Al Bawab, A., Alshawawreh, F., Abu-Dalo, M., Al-Rawashdeh, M., and Bozeya A. "Separation of soluble phenolic compounds from olive mill wastewater (OMW) using modified surfactants", Fresenius Environ. Bull., 26, 1949-1958 (2017).

Al Bawab, A., Ghannam, N., Abu-Mallouh, S., Bozeya, A., and Abu-Zurayk R. "Olive mill wastewater treatment in Jordan: A Review", Proceedings of IOP Conf. Ser.: Mater. Sci. Eng., 305, 012002 (2018a).

Al Bawab, A., Ghannam, N., Abu-Zurayk, R., Odeh, F., Bozeya, A., Abu Mallouh, S., Al-Rawashdeh, N., and Abu-Dalo M. "Olive Mill Wastewater Remediation with Granular Activated Carbon Impregnated with Active Materials", Fresenius Enviro. Bull., 24, 2118-2126 (2018b).

Al Bsoul, A., Hailat, M., Abdelhay, A., Tawalbehc, M., Jum'h I., and Bani-Melhem K. "Treatment of olive mill effluent by adsorption on titanium oxide nanoparticles", Sci. of the Total Environ., 688, 1327-1334 (2019).

Alaoui, N.S., El Laghdach, A., Stitou, M., and Bakkali A. "Treatment and valorization of olive mill wastewaters", Mediterranean J. of Chemistry, 5, 458-464 (2016).

Al-Essa, K. "Activation of Jordanian Bentonite by Hydrochloric Acid and Its Potential for Olive Mill Wastewater Enhanced Treatment", J. of Chemistry, 2018, 1-10 (2018).

Alique, D., Bruni, G., Sanz, R., Calles, J. A., and Tosti S. "Ultra-Pure Hydrogen via Co-Valorization of Olive Mill Wastewater and Bioethanol in PdMembrane Reactors", Processes, 8, 1-16, (2020).

Allaoui, S., Bennani, M. N., Ziyat, H., Qabaqous, O., Tijani, N., and Ittobane N. "Kinetic Study of the Adsorption of Polyphenols from Olive Mill Wastewater onto Natural Clay: Ghassoul”, J. of Chemistry, 2020, 1-11 (2020).

Al-Shaweesh, M., Matouq, M., Al-Kabariti D., Khamash D., Al-Zawaidah S., Hindiyeh M., and Omar W. "Olive mill wastewater (OMW) treatment by using ferric oxide dephenolization and chemical oxygen demand removal", Global NEST Journal, 20, 558-563 (2018).

Amaral-Silva, N., Martins, R. C., Castro-Silva, S., and Quinta-Ferreira R. "Integration of traditional systems and advanced oxidation process technologies for the industrial treatment of olive mill wastewaters", Environmental Technology, 37, 2524-2535 (2016).

Ayman Oz, N., and Cagla Uzun Eker A. "Simultaneous hydrogen production and pollutant removal from olive mill wastewaters using electrohydrolysis process", Chemosphere, 232, 296-303 (2019). 
Azzam, M. O. "Olive mills wastewater treatment using mixed adsorbents of volcanic tuff, natural clay, and charcoal”, J. of Environ. Chem. Eng., 6, $2126-2136$ (2018).

Azzam, M. O., Al-Gharabli, S. I., and Al-Harahsheh M. "Olive mills wastewater treatment using local natural Jordanian clay", Desalination and Water Treatment, 53(3), 627-636 (2015).

Azzaz, A. A., Jeguirim, M., Kinigopoulou, V., Doulgeris, C., Goddard, M.-L., Jellali, S., and Ghimbeu C. "Olive mill wastewater: From a pollutant to green fuels, agricultural and water source and bio-fertilizer - Hydrothermal carbonization”, Sci. of the Total Environ., 733, 1-12 (2020).

Benekos, A. K., Zampeta, C., Argyriou, R., Economou, C. N., Triantaphyllidou I. E., Tatoulis T. I., Tekerlekopoulou, A. G., and Vayenas D. V. "Treatment of table olive processing wastewaters using electrocoagulation in laboratory and pilot-scale reactors", Proc. Safety and Environ. Prot., 131, 38-47 (2019).

Department of Statistics, "Agricultural Statistics Bulletin (National Strategy for Agricult ural Development Surveys)", The Hashemite Kingdom of Jordan (2018).

Department of Strategic Planning and Institutional Development, Ministry of Agriculture “Annual Report”, The Hashemite Kingdom of Jordan (2019).

Domingues, E., Gomes, J., Quina, M. J., Quinta-Ferreira, R. M., and Martins R. C. “Detoxification of Olive Mill Wastewaters by Fenton's Process”, Catalysts, 8, 1-17 (2018).

El Moussaoui, T., Jaouad, Y., Mandi, L., Marrot, B., and Ouazzani N. "Biomass behaviour in a conventional activated sludge system treating olive mill wastewater", Environ. Tech., 39, 190-202 (2018).

Elkacmi, R., Boudouch, O., Hasib, A., Bouzaid, M., and Bennajah M. "Photovoltaic electrocoagulation treatment of olive mill wastewater using an externalloop airlift reactor", Sustain. Chem. and Pharmacy, 17, 100274 (2020).

Elmansour, T., Mandi, L., Ahmali, A., Elghadraoui, A., Aziz, F., Hejjaj, A., Delbuba, M., and Ouazzani N. "Effect of polyphenols on activated sludge biomass during the treatment of highly diluted olive mill wastewaters: biomass dynamics and purifying performances", Water Sci. and Tech., 82, 1416-29 (2020).

Enaime, G., Baçaoui, A., Yaacoubi, A., Wichern, M., and Lübken M. "Olive mill wastewater pretreatment by combination of filtration on olive stone filters and coagulation-flocculation”, Environ. Tech., 40, 2135-2146 (2019).

Erdem, S., Bag, H., Can Yarimtepe, C., Ince, O., and Ayman N."Hydrogen gas production and pollutant removal from olive mill wastewater by electrohydrolysis”, WIT Trans. on Ecology and the Environ., 205, 271-277 (2016).

Esteves, B. M., Rodrigues, C. S., Maldonado-Hódar, F. J., and Madeira L. "Treatment of high-strength olive mill wastewater by combined Fenton-like oxidation and coagulation/flocculation", J. of Environ. Chem. Eng., 7, 1-12 (2019).

Fraga, M. C., Sanches, S., Crespo, J. G., and Pereira V. "Assessment of a New Silicon Carbide Tubular Honeycomb Membrane for Treatment of Olive Mill Wastewaters", Membranes, 7, 1-16 (2017).

Fraga, M. C., Huertas, R. M., Crespo, J.G., and Pereira V. J. "Novel Submerged Photocatalytic Membrane Reactor for Treatment of Olive Mill Wastewaters", Catalysts, 9, 1-16 (2019).

Gikas, G. D., Tsakmakis, I. D., and Tsihrintzis, V. "Hybrid Natural Systems for Treatment of Olive mill Wastewater", J. Chem. Technol. Biotech., 93, 800-809 (2018).

Iakovides, I. C., Pantziaros, A. G., Zagklis, D. P., and. Paraskeva C. "Effect of electrolytes/polyelectrolytes on the removal of solids and organics from olive mill wastewater", J. Chem. Technol. Biotec., 91, 204-211 (2016).

Ibrahimoglu, B., and Yilmazoglu M. "Disposal of olive mill wastewater with DC arc plasma method", J. of Environ. Manag., 217, 727-734 (2018).

Jomaa, N., and Hourieh Y. "Integrated Process for the Treatment of Olive Oil Mill Waste Water (OMW)”, Chemistry Res. J., 5, 121-129 (2020).

Khani, M. R., Mahdizadeh, H., Kannan, K., Kalankesh, L. R., Kamarehei, B., Baneshi, M. M., and Shahamat Y. "Olive Mill Wastewater (OMW) Treatment by Hybrid Processes of Electrocoagulation/Catalytic Ozonation and Biodegradation”, Environ. Eng. \& Manag. J., 19, 1401-1410 (2020).

Kilic, M. Y., Abdelraheem, W. H., He, X., Kestioglu, K., and Dionysiou D. "Photochemical treatment of tyrosol, a model phenolic compound present in olive mill wastewater, by hydroxyl and sulfate radical-based advanced oxidation processes (AOPs)", J. of Haza. Mater., 367, 734-742 (2019).

Kirmaci. A., Duyar A., Akgul V., Akman D., and Cirik K. "Optimization of combined ozone/Fenton process on olive mill wastewater treatment" Aksaray University J. of Sci. and Eng., 2, 52-62 (2018).

Malvis, A., Hodaifa, G., Halioui, M., Seyedsalehi, M., and Sánchez S. "Integrated process for olive oil mill wastewater treatment and its revalorization through the generation of high added value algal biomass", Water Res., 151, 332-342 (2019).

Niazmand, R., Jahani, M., Sabbagh, F., and Rezania S. "Optimization of Electrocoagulation Conditions for the Purification of Table Olive Debittering Wastewater Using Response Surface Methodology”, Water, 12, 1-18 (2020).

Sanches, S., Fraga, M. C., Silva, N. A., Nunes, P., Crespo, J. G., and Pereira V. "Pilot scale nanofiltration treatment of olive mill wastewater: a technical and economical evaluation”, Environ. Sci. Pollut. Res., 24,3506-3518 (2017).

Sciascia, L. Casella, S., Cavallaro, G., Lazzara, G., Milioto, S., Princivalle, F., and Parisi F. "Olive mill wastewaters decontamination based on organo-nanoclay composites", Ceramics Int., 45, 2751-2759 (2019).

Sponza D.T., and Balaban M. "Treatment of Olive Mill Effluent by Nano-Zinc Oxide-Magnetite", American J. of Nanotech. \& Nanomedicine, 1, 028-042 (2018).

Stoller, M., Ochando-Pulidob, J.M., Vilardia, G., Vuppalaa, S., Bravia, M., Verdonea, N., and Di Palmaa L. "Technical and Economic Impact of Photocatalysis as a Pretreatment Process Step in Olive Mill Wastewater Treatment by Membranes", Chem. Eng.Trans., 57, 1171-1176 (2017).

Sygouni, V., Pantziaros, A. G., Iakovides, I.C., Sfetsa, E., Bogdou, P. I., Christoforou, E. A., and Paraskeva C. "Treatment of Two-Phase Olive Mill Wastewater and Recovery of Phenolic Compounds Using Membrane Technology", Membranes, 9, 1-16 (2019).

Tsagaraki, E., Lazarides, H. N., and Petrotos K. B. “Olive Mill Wastewater Treatment” In: Oreopoulou V., Russ W. editors. Utilization of By-Products and Treatment of Waste in the Food Industry. Boston, MA.: Springer, 2007.

Vavouraki, A. I. "Removal of Polyphenols from Olive Mill Wastewater by FPX 66 Resin: Part II. Adsorption Kinetics and Equilibrium Studies", Int. J. Waste Resour., 10, 1-7 (2020).

Vavouraki, A. I., Dareioti, M. A., and Kornaros M. "Olive Mill Wastewater (OMW) Polyphenols Adsorption onto Polymeric Resins: Part I—Batch Anaerobic Digestion of OMW", Waste Biomass Valor, (2020).

Volpe, M., Wüst, D., Merzari, F., Lucian, M., Andreottola, G., Kruse, A., and Fiori L. "One stage olive mill waste streams valorisation via hydrothermal carbonization", Waste Manag., 80, 224-234 (2018). 
Vuppala, S., Bavasso, I., Stoller, M., Di Palma, L., and G. Vilardi “Olive mill wastewater integrated purification through pre-treatments using coagulants and biological methods: experimental, modelling and scale-up', J. of Cleaner Prod., 236, 1-11 (2019).

Yassine, W., Akazdam, S., Zyade, S., and Gourich B. "Treatment of Olive Mill Wastewater Using Electrocoagulation Process", J. of Appl. Surfaces and Interfaces, 4, 24-30 (2018).

Ziati, M., Khemmari, F., Cherifi, O., and Didouche F.Y. "Removal of Polyphenols from Olive Mill Wastewater by Adsorption on Activated Carbon Prepared from Peach Stones", Rev. Roum. Chim., 62, 865-874 (2017). 